Editorial

\title{
The game of fear, blame and shame: stigma of HIV, a major public health debacle
}

Volume I Issue I - 2014

\author{
Sohail Rana, Chandni Parikh \\ Department of Pediatrics and Child Health, Howard University \\ College of Medicine, USA
}

Correspondence: Sohail Rana, Department of Pediatrics and Child Health, Howard University College of Medicine, 204I Georgia Avenue, N.W.,Washington DC 20060, USA, Tel 202 865-6498, Fax 202-865-4346, Email srana@howard.edu

Received: April 29, 20I4 | Published: May 05, 2014 of the last "d" like it was a playful note of music the keep singing each time we met. Chelsea had a great sense of humor. She knew it, too and dreamed of becoming a standup comedian. But behind her laughter was a broken heart. Chelsea's own family made her feel dirty because of her illness. They kept her dishes separate from their own and sanitized the places and spaces where she sat or touched. When her cousin found out that she had HIV, she refused to hug Chelsea or even touch her.

The feeling of rejection was crippling. Chelsea gave up her fightshe stopped taking her life-saving medications. The pills reminded Chelsea that she had HIV and the pain of rejection. Chelsea could have lived a normal life if she had continued with her medications; she gave up because of stigma.

Three decades after the discovery of HIV, stigma, still surrounds the illness and those living with it. Many have been permanently scarred by the stigma. Around the world, every 16 seconds, someone gets infected with HIV and another loses their life to HIV. Still, people are afraid of being tested, going to doctors, filling their prescriptions, and taking them regularly. Health-related stigma, blame and shame aren't limited to HIV. Leprosy, sexually transmitted diseases, mental illnesses, tuberculosis, diabetes, and obesity are just some of the examples of stigmatized illnesses. However, HIV is considered to be the most stigmatized disease in medical history. In the early days of HIV, stigma trailed the illness and was crushing-some physicians and emergency personnel refused to treat and care for those with HIV.

Thirty years ago at Howard University Hospital, we too were on the frontline of HIV, caring for children, and working without medications to tackle the disease. At that time, there were none. Information regarding modes of transmission was preliminary. HIV not only caused wasting but was usually deadly. In the early years of HIV, it was known as a disease of gay men, sex workers, and intravenous drug users. HIV became seriously stigmatized because some believed these groups deserved to be plagued because of their behavior. We saw a different face of HIV. We cared for women who became drug dependent because they were sexually abused before they reached puberty. We cared for children who became infection at birth and boys and girls who were sexually abused. We saw nothing but victims of society's ills. Stigma still knows no age. Ryan White- born with hemophilia in 1971 and diagnosed with HIV at age 13 - tried to live a normal life, but was shunned and banned from his school and church. The White family won many of the legal battles they waged when Ryan was alive, but continued to lose to hate, ignorance, and discrimination. Even after his death, Ryan's grave site was repeatedly vandalized and desecrated.We've watched over the years as stigma

stoked AIDS' fire, kept those who needed testing and treatment away from clinics, and crippled and killed lives in ways that HIV-AIDS could not. Ki Moon, the Secretary General of the United Nations called stigma the single most important barrier to public action. He is right. Many patients waste their precious energies vigorously hiding their diagnosis, living in fear of discrimination, shunning, and shame, or worse - all because they have HIV.

Today, almost 30 after we cared for our first child with HIV, much has changed. We have more than 2 dozen effective medications in our HIV treatment arsenal. Used appropriately, these drugs can effectively control HIV, maybe even indefinitely. Access to these medications has improved not only in the developed world but also in many developing countries. ${ }^{1}$ But while there appears to be some decline in the number of new infections, the goal of "zero new infections" likely won't be achievable in the foreseeable future.

In the U.S., about 1.1million people are living with HIV and one person becomes infected every 10minutes. Of those 902,000 have been diagnosed and almost 200,000 are not aware of their HIV infection, 726,000 have been linked to care, and more than 250,000 are not. Of those linked to care 407,000 are retained in care; 319,000 are not receiving regular follow up, and only 363,000 are receiving therapy. Having an undetectable viral load remains the gold standard of successful treatment, but only 275,000 infected individuals can claim that. We do not need advanced mathematical models to show us the glaring gaps in diagnosis, care, and treatment. Many people do not get tested because they fear being labeled.

I had not seen Raquel and her child for almost a year. They are both infected with HIV and I have been her child's doctor since birth when HIV was diagnosed. When asked why she had missed so many appointments for her child, Raquel burst into tears. She had been shamed by those who were medically trained to care for her.

"I hate all hospitals, I hate doctors." As we listened to her story, we were disappointed and taken aback, especially since we felt that our team had a good relationship with her. After a long consoling hug, Raquel continued her story. 
"I was told that I needed surgery to deliver my daughter and it was scheduled at 8 a.m. At 7 a.m. I was told about the results of my HIV tests, which were positive. I was shocked but I was more worried about the surgery and my baby. It was 8 a.m., then 9 a.m. and then 11 a.m. I kept asking when I am going for surgery. I was told that they are still trying to find somebody who would deliver my baby." Sobbing, she continued, "I had never felt so low in my life, they made me feel dirty and untouchable. It was clear to me that nobody wanted to operate on me because of my HIV. Ever since then, every time I have to go to a hospital or a doctor, I start panicking and those feelings come rushing back."

Adewuya et al. $^{2}$ examined the probability of developing posttraumatic stress disorder (PTSD) after experiencing intense stigma. 27 percent of participants reported HIV stigma-related PTSD.

Stigma's reach is global. When 2,035 patients in 12 countries who were being treated for HIV were interviewed, nearly half reported experiencing shunning-encountering someone who was afraid to have casual contact with them because of their HIV infection. And 1 in 4 surveyed said that others would not share food with them or kiss them; 37 percent reported feelings of loneliness and 27 percent were depressed. $^{3}$

Individuals suffering from HIV are not paranoid or dreaming. Fear and bias among the general U.S. population toward those with HIV is real and far reaching. According to a 2012 Kaiser Family Foundation/ Washington Post survey ${ }^{4}-20$ percent reported that they would be uncomfortable working with somebody with HIV; 33 percent would be uncomfortable having a roommate with HIV, 44 percent said they would be uncomfortable having food prepared by someone who has HIV, and 26 percent would be uncomfortable if their child had an HIV positive teacher.

Sometimes there are moments of hope. "Can you call me, it is urgent" read a recent email message from my patient Tamika. She was ecstatic. Tamika had the courage to disclose her HIV diagnosis to her boyfriend. He didn't turn and run. He told Tamika that he loved her, something he's stated many times before, but each time, her response was the same, "but you don't know me." With no more secrets, Tamika can say I love you, too. Medicine and science can provide treatments but healing is not possible without acceptance and love.

Stigma continues to rob many with HIV of their basic human rights Believe it or not, 41 countries bar those with HIV from traveling; the U.S. military bans recruitment and enlistment of those who are infected with HIV, and more laws are criminalizing HIV. For many, having HIV is equivalent to social death. Even among physicians, a survey revealed that many have persistent misconceptions and negative attitudes towards those with HIV. This is a startling and sad revelation after 30 years of HIV-AIDS and dramatic advances in the science.
Ultimately, we must all realize that medical care is a very small determinant of health. We will never overcome and control HIV without directing resources to changing people's attitude towards HIV and other stigmatized illnesses. Today, preventing, diagnosing, treating, and maintaining patients in treatment programs demands that we are intentional about de-stigmatizing HIV. Improving HIVspecific cultural competence among physicians, health care providers, and staff is one starting place. Stigma, like smoking, is a major public health hazard. It sickens and kills, and is out of control. As our team at Howard with our community partners works towards organizing the 5th International Conference on HIV Stigma and establish a Center for Human Rights in Health at Howard, we are humbled by our successes and are even more aware of the major barriers that remain. If we can do something about smoking, we can also find ways to tackle stigma. The time is now for healing the evil that causes us to treat some patients and some illnesses differently than others. We can only achieve better health outcomes and zero infections if we can make all human beings feel accepted and loved irrespective of their illness. Start with the person in the mirror. When we start playing the game of fear, blame and shame, everybody loses.

\section{Acknowledgments}

None.

\section{Conflicts of interest}

The authors have no conflict of interests related to this publication and have not received any grants.

\section{Funding}

None.

\section{References}

1. Harris J, Pillinger M, Fromstein D, et al. Risk factors for medication non-adherence in an HIV infected populationin the Dominican Republic. AIDS Behavior. 2011;15(7):1410-1415.

2. Adewuya AO, Afolabi MO, Ola BA, et al. Post-traumatic stress disorder (PTSD) after stigma-related events in HIV infected individuals in Nigeria. Soc Psychiatry Psychiatr Epidemiol. 2009;44(9):761-766.

3. Nachega JB, Morroni C, Zuniga JM, et al. HIV-related stigma, isolation, discrimination, and serostatus disclosure: a global survey of 2035 HIV-infected adults. J Int Assoc Physicians AIDS Care (Chic). 2012;11(3):172-178.

4. The Washington Post/Kaiser Family Foundation 2012 Survey of Americans on HIV/AIDS. 2014. 